\title{
lodine and Thyroid Function Status, and Anti-thyroid Peroxidase Antibody among Pregnant Women in Eastern Nepal
}

\author{
Lalit Narayan Chaudhary, ${ }^{1}$ Saroj Khatiwada, ${ }^{1}$ Basanta Gelal, ${ }^{1}$ Sharad Gautam, ${ }^{1}$ Madhab Lamsal, ${ }^{1}$ Hanoon \\ Pokharel, ${ }^{2}$ Nirmal Baral ${ }^{1}$
}

1'Department of Biochemistry, B P Koirala Institute of Health Sciences, Sunsari, Nepal, ${ }^{2}$ Department of Obstetrics and Gynaecology, B P Koirala Institute of Health Sciences, Sunsari, Nepal.

\begin{abstract}
Background: Iodine deficiency, thyroid dysfunction and development of thyroid autoimmunity during pregnancy may affect mother and the developing fetus. This study was carried out to find iodine status, thyroid dysfunction and thyroid autoimmunity among pregnant women.

Methods: Ninety two pregnant women from three districts of eastern Nepal (Sunsari, Morang and Jhapa) were enrolled for the study, and urine and blood samples were collected. Urinary iodine concentration (UIC), free thyroxine (free T4), thyroid stimulating hormone (TSH), thyroglobulin and anti-thyroid peroxidase (TPO) antibody levels were estimated.

Results: The median UIC, mean free T4 and TSH, median thyroglobulin and anti-TPO antibody in the pregnant women were $282.2(158.42-376) \mu \mathrm{g} / \mathrm{L}, 1.14 \pm 0.41 \mathrm{ng} / \mathrm{dL}, 4.57 \pm 2.56 \mathrm{IU} / \mathrm{mL}, 6.5(4.0-11.0) \mathrm{ng} / \mathrm{mL}, 1.52$ (0.97-2.23) IU/ $\mathrm{mL}$ respectively. In sufficient $(<150 \mu \mathrm{g} / \mathrm{L})$, adequate $(150-249 \mu \mathrm{g} / \mathrm{L})$ and above requirements $(250-499 \mu \mathrm{g} / \mathrm{L})$ iodine intake was observed in 17 (18.5\%), 22 (23.9\%) and 53 (57.6\%) women respectively. Subclinical hypothyroidism and overt hypothyroidism were seen in $18(19.5 \%)$ and $1(1.1 \%)$ women, respectively. Elevated thyroglobulin (>40 ng/ $\mathrm{mL}$ ) and positive anti-TPO antibody was observed in three (3.26\%) women for both.

Conclusions: Iodine intake was sufficient among pregnant women recently, however, chronic iodine deficiency persisted in small fraction of pregnant women. Mild thyroid dysfunction was common, and thyroid autoimmunity was present in small portion of Nepalese pregnant women population.

Keywords: Anti-thyroid peroxidase antibody; Iodine deficiency; Nepal; pregnant women; thyroid dysfunction.
\end{abstract}

\section{INTRODUCTION}

lodine deficiency during childhood and pregnancy has greater negative effects than in other population. ${ }^{1,2}$ Pregnancy has a profound impact on the thyroid gland and thyroid function. ${ }^{3}$ Thus, thyroid disorders have been reported more often in women during pregnancy. 4,5 Uncorrected thyroid dysfunction during pregnancy has adverse effects on fetal and maternal well-being. ${ }^{6}$ Autoimmune thyroid disease can be the common cause for both hyperthyroidism and hypothyroidism in women, and development of antibodies to thyroid peroxidase (TPO) or thyroglobulin during pregnancy is associated with rise in a number of adverse pregnancy outcomes. ${ }^{7}$ Anti-TPO antibodies appear in around 10\% of women in early pregnancy, and are also associated with decreased thyroid function during gestation with possible development of hypothyroidism. ${ }^{6}$ Physiological changes during early pregnancy may lead to higher rate of thyroid disorders in second and third trimesters. ${ }^{3}$ lodine nutrition has been progressively improving in children in eastern Nepal. ${ }^{8-11}$ However, little is known about iodine nutritional status, thyroid dysfunction and thyroid autoimmunity among pregnant women in such areas. So, we conducted the study among pregnant women of eastern Nepal to find iodine status, thyroid function and thyroid autoimmunity in such population.

\section{METHODS}

The study was carried out in the department of biochemistry of BP Koirala Institute of Health Sciences

Correspondence: Mr Saroj Khatiwada, Department of Biochemistry, B P Koirala Institute of Health Sciences, Dharan, Sunsari, Nepal. Email: khatiwadasaroj22@ gmail.com. 
(BPKIHS), Dharan, Nepal with an aim to explore iodine status, thyroid function and anti-TPO antibody among pregnant women of eastern Nepal. Ninety-two pregnant women in the second and third trimester were enrolled in this study from primary health care center of three districts namely; Sunsari $(n=58)$, Morang $(n=13)$ and Jhapa ( $\mathrm{n}=21)$, during July 2013 to August 2014. Inclusion criteria were pregnant women in second and third trimester of gestation. Exclusion criteria were pregnant women taking drugs that interfere in thyroid function, those having a current history of iodine supplement, pregnant women with complications and those who do not want to participate in the study. Demographic information was collected from each woman, and urine $(10 \mathrm{ml})$ and blood $(2 \mathrm{ml})$ samples were collected after taking consent from each women. The ethical clearance for the study was provided by Ethical Review Board of BP Koirala Institute of Health Sciences.

Urine and blood samples were transported to the biochemistry laboratory of BPKIHS and maintained at -20C until analysis. Urinary iodine concentration (UIC) was estimated in urine samples using ammonium persulphate digestion method (APDM) in microplate which is based on Sandell-Kolthoff reaction. ${ }^{12}$ Blood samples were analyzed for thyroid hormones (free thyroxine (free T4) and thyroid stimulating hormone (TSH)), thyroglobulin and anti-TPO antibody. Measurement of serum free T4, TSH and thyroglobulin was done by ELISA technique using commercial kits from Diametra, and anti TPOantibodies by Is-anti-TPO IgG kits from Diamedix. The reference ranges provided by the kits manufacturer for free T4, TSH, thyroglobulin and anti-TPO antibody were 0.8-2.2 ng/dL, 0.39-6.16 mlU/L, $<40.0 \mathrm{ng} / \mathrm{mL}$, and $<20$ $\mathrm{IU} / \mathrm{ml}$ for negative, $20-29.9 \mathrm{IU} / \mathrm{mL}$ for equivocal and $\geq 30 \mathrm{IU} / \mathrm{ml}$ for positive antibody detection respectively.
Using above reference ranges (since reference ranges for Nepalese women during pregnancy have not been established and reference ranges tend to vary according to the assay method used), women were classified for thyroid function status, elevated thyroglobulin and positive anti-TPO antibody. Euthyroid was defined as condition of normal level of TSH and free T4. Overt hypothyroidism was defined as $\mathrm{TSH}>6.16 \mathrm{mIU} / \mathrm{L}$ and free $\mathrm{T} 4<0.8 \mathrm{ng} / \mathrm{dL}$. Subclinical hypothyroidism was defined as $\mathrm{TSH}>6.16 \mathrm{mIU} / \mathrm{L}$ and normal free T4 level.

The results from the studywere entered in Microsoft Excel 2010 and analyzed using SPSS 20.0 software. A normally distributed variable was expressed as mean \pm SD, and non-normally distributed variable as median and interquartile range. Independent t test, Mann-Whitney test and Chi-square test were applied at $95 \%$ confidence interval to test for the significance. Pearson's and Spearman's correlation analysis was carried out to estimate correlation between quantitative variables. A p-value less than 0.05 wasconsidered statistically significant.

\section{RESULTS}

The study comprised 92 pregnant women, 52 in the second trimester and 40 in the third trimester. The mean age of pregnant women was $24.45 \pm 4.4$ years (second trimester: $24.4 \pm 4.65$ years and third trimester: $24.5 \pm 4.06$ years, $p=0.918$ ). The median UIC, mean free T4 and TSH, and median thyroglobulin and anti-TPO antibody were $282.2 \mu \mathrm{g} / \mathrm{L}(158.42-376), 1.14 \pm 0.41 \mathrm{ng} /$ $\mathrm{dL}, 4.57 \pm 2.56 \mathrm{mIU} / \mathrm{L}, 6.5 \mathrm{ng} / \mathrm{mL}(4.0-11.0)$ and $1.52 \mathrm{IU} /$ $\mathrm{mL}(0.97-2.23)$ respectively. Biochemical parameters in pregnant women in second and third trimester are shown in Table 1.

Table 1. Biochemical parameters in the study population.

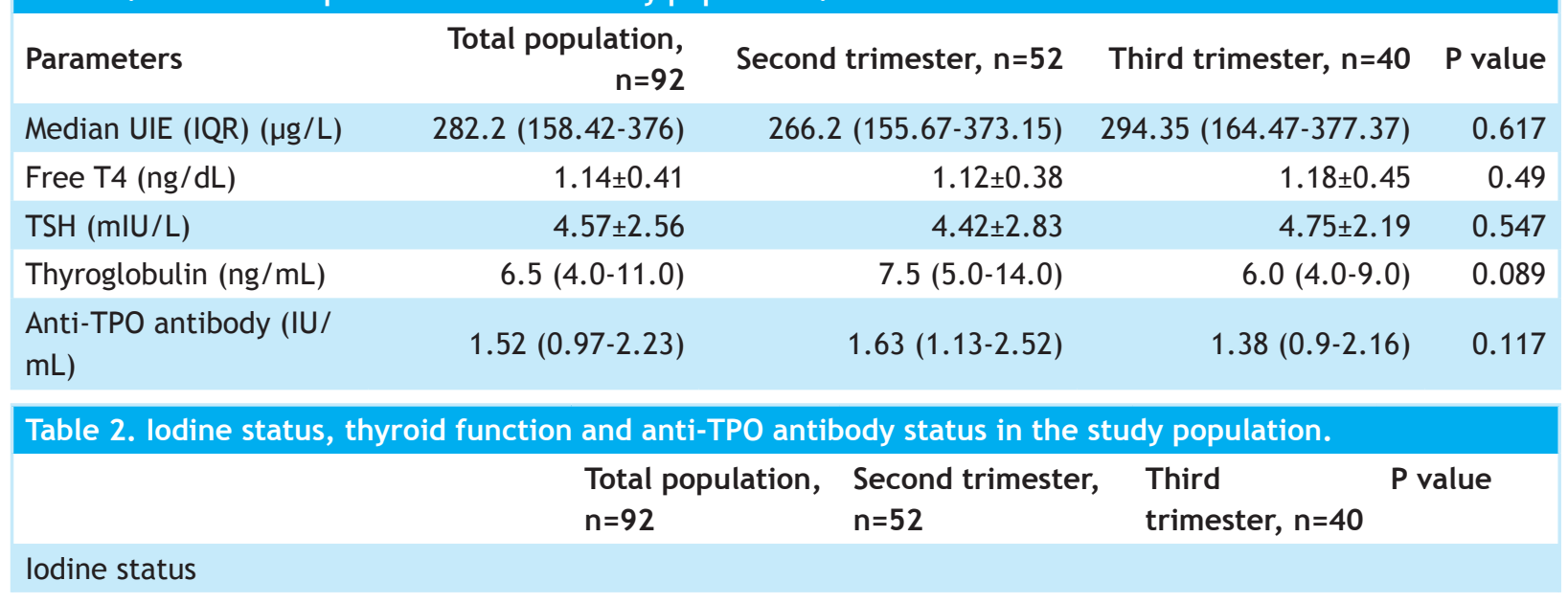


Iodine and Thyroid Function Status, and Anti-thyroid Peroxidase Antibody among Pregnant Women

\begin{tabular}{|c|c|c|c|c|}
\hline Insufficient $(<150 \mu \mathrm{g} / \mathrm{L})$ & 17 & 11 & 6 & \multirow[t]{3}{*}{0.665} \\
\hline Adequate (150-249 $\mu \mathrm{g} / \mathrm{L})$ & 22 & 13 & 9 & \\
\hline Above requirements $(250-499 \mu \mathrm{g} / \mathrm{L})$ & 53 & 28 & 25 & \\
\hline \multicolumn{5}{|l|}{ Thyroid function } \\
\hline Euthyroid & 73 & 42 & 31 & \multirow[t]{3}{*}{0.797} \\
\hline Subclinical hypothyroidism & 18 & 9 & 9 & \\
\hline Overt hypothyroidism & 1 & 1 & - & \\
\hline Elevated thyroglobulin $(>40 \mathrm{ng} / \mathrm{mL}$ ) & 3 & 2 & 1 & 1.0 \\
\hline Positive anti-TPO antibody & 3 & 1 & 2 & 0.33 \\
\hline
\end{tabular}

In the study population, insufficient $(<150 \mu \mathrm{g} / \mathrm{L})$, adequate $(150-249 \mu \mathrm{g} / \mathrm{L})$ and above requirements $(250$ $499 \mu \mathrm{g} / \mathrm{L})$ iodine status was observed in $17(18.5 \%)$, $22(23.9 \%)$ and $53(57.6 \%)$ women respectively. Using reference interval from kits manufacturer, subclinical hypothyroidism and overt hypothyroidism was seen in $18(19.5 \%)$ and one (1.1\%) women respectively. Elevated thyroglobulin (>40 $\mathrm{ng} / \mathrm{mL}$ ) and positive antiTPO antibody was observed in three (3.26\%) women for both. lodine status, thyroid function and anti-TPO antibody status in the women according to second and third trimester is shown in table 2. All of the women with positive anti-TPO were euthyroid. Among 17 women with insufficient UIC, subclinical hypothyroidism and elevated thyroglobulin was observed in four and one women respectively. Among the three women with elevated thyroglobulin, one woman had insufficient UIC, subclinical hypothyroidism and overt hypothyroidism for each. Hypothyroid women had higher median anti-TPO antibody level than euthyroid women but not significant (1.55 IU/mL versus $1.48 \mathrm{IU} / \mathrm{mL} ; \mathrm{p}=0.866)$.

The correlation of UIC with free T4, TSH, thyroglobulin and anti-TPO was $0.012(p=0.908), 0.001 \quad(p=0.991)$, $-0.017(p=0.875)$ and $0.248(p=0.017)$ respectively. The correlation of thyroglobulin with free T4, TSH and antiTPO were $-0.072(p=0.493), 0.151(p=0.152)$ and 0.104 $(p=0.322)$ respectively. The correlation of anti-TPO with free T4 and TSH were $-0.142(p=0.178)$ and -0.121 $(p=0.25)$ respectively (Table2).

\section{DISCUSSION}

Pregnancy is a condition accompanied by increase in energy and nutrients requirement. Pregnant women require $250 \mu \mathrm{g}$ intake of iodine per day, and UIC is a good indicator of recent iodine intake. ${ }^{2,13}$ The median UIC among pregnant women in the present study was $\mathbf{2 8 2 . 2}$ $\mu \mathrm{g} / \mathrm{L}$, which indicates more than adequate iodine intake among pregnant women of eastern Nepal. However, $17(18.5 \%)$ women had $\mathrm{UIC}<150 \mu \mathrm{g} / \mathrm{L}$, which indicates insufficient iodine intake in those women recently. There are limited data on iodine status during pregnancy in Nepal, however, in school children there has been continuous improvement in iodine nutrition. ${ }^{1,8-11}$ In one study, Schulze et al. observed mild iodine deficiency in pregnant and lactating women of rural southern plains (Terai region) of Nepal. ${ }^{13}$ In a study in India, median UIC was $203 \mu \mathrm{g} / \mathrm{L}$ and $211 \mu \mathrm{g} / \mathrm{L}$ at 17 and 34 weeks of pregnancy respectively, whereas in another study, median (range) UIC in the first, second, and third trimesters was $285 \mu \mathrm{g} / \mathrm{L}$ (102-457), $318 \mu \mathrm{g} / \mathrm{L}$ (102-805), and $304 \mu \mathrm{g} / \mathrm{L}(172-859)$ respectively. ${ }^{14,15}$

We estimated thyroglobulin, the marker for long term iodine nutrition over a period of months or years, for exploring iodine status in Nepalese pregnant women. In the present study, the median thyroglobulin was 6.5 $\mathrm{ng} / \mathrm{mL}$, and three women (3.26\%) had increased level of thyroglobulin ( $>40 \mathrm{ng} / \mathrm{mL}$ ). Thyroglobulin level $>40 \mathrm{ng} / \mathrm{mL}$ indicates iodine deficiency in individuals. ${ }^{16}$ Our results indicate that most women had sufficient iodine nutrition over a period of time, and only three women had chronic iodine deficiency. Our findings suggest that most pregnant women have sufficient iodine nutrition over a period of time, however, many women seem to have inadequate iodine intake recently. In a study in Sri Lanka, median thyroglobulin was $21.4 \mathrm{IU} / \mathrm{L}$ among pregnant women in $39.33( \pm 1.37)$ weeks of gestation. ${ }^{17}$ In a study done in France,the median thyroglobulin in pregnant women was $16.2 \mu \mathrm{g} / \mathrm{L}$, and it did not differ across trimesters, and was significantly higher than in the control group of non-pregnant adults $(11.7 \mu \mathrm{g} / \mathrm{L})\{\mathrm{p}=0.02\} .{ }^{18}$ Because of the harmful consequences of iodine deficiency on mother and fetus health, it is recommended that pregnant women take extra iodine than normal adults. ${ }^{17}$ Universal salt iodization has been the most common strategy of eliminating iodine deficiency in landlocked countries, and this been successful in Nepal with increasing number of households consuming adequately iodized salt and median UIC among school children is rising. ${ }^{1,19}$

Thyroid dysfunction has been observed as the most frequent endocrine disorder in pregnant women. ${ }^{5} \mathrm{We}$ observed thyroid dysfunction in 19 (20.65\%) pregnant 
women and the most common dysfunction was subclinical hypothyroidism(18, 19.56\%) when the upper normal cutoff value for TSH was taken $6.16 \mathrm{mIU} / \mathrm{L}$. Assay specific reference ranges for thyroid hormones according to pregnancy trimester were unavailable for the kits used in study, so we could not classify the thyroid status accordingly in the present study. The rate of thyroid dysfunction among pregnant women would jump to $68.5 \%(n=63)$ if thyroid dysfunction was classified on the basis of trimester specific recommendation for thyroid function by American Thyroid Association which has suggested reference range for TSH if no trimesterspecific reference ranges are available in the laboratory (first trimester, 0.1-2.5 mlU/L; second trimester, 0.2$3.0 \mathrm{mIU} / \mathrm{L}$; third trimester, $0.3-3.0 \mathrm{mIU} / \mathrm{L}) .^{3}$ Though, previous findings about thyroid function in Nepalese pregnant women are not available, various studies in metabolic syndrome, diabetes mellitus and kidney disease patients have revealed thyroid dysfunction in large fraction of study patients with subclinical hypothyroidism as the commonest disorder. ${ }^{20-22}$ Recently, a study in school children of eastern Nepal reported thyroid dysfunction in $19.4 \%$ of school age children, and $16.3 \%$ had subclinical hypothyroidism. ${ }^{23}$ When focused with thyroid disorders among pregnant women in other countries, varied rate were reported. Study by Singh et al., found subclinical hypothyroidism and overt hypothyroidism in $18 \%$ and $4.5 \%$ among pregnant women in first and second trimester respectively. ${ }^{24}$ In another study in South West Bengal, subclinical hypothyroidism was reported in $32.94 \%$ pregnant women during first trimester. ${ }^{25}$ It has been observed that thyroid dysfunction during pregnancy is associated with increased risk of termination of pregnancy and abnormalities in mother and fetus. ${ }^{6}$

Autoantibodies against TPO enzyme are predominant fractions of antibodies seen in autoimmune thyroid disorders. ${ }^{3}$ In this study, the median anti-TPO was 1.52 $\mathrm{IU} / \mathrm{mL}$, and three women $(3.26 \%$ ) had positive anti-TPO antibody, and normal thyroid function was seen in all antiTPO positive women. The prevalence of autoimmunity toward thyroid protein tends to vary among different ethnic groups and regions. In a study among Indian pregnant women in first trimester, elevated anti-TPO was observed in $27.8 \%$ pregnant women. ${ }^{26}$ In a study among Spanish pregnant women, anti-TPO level was 0.08 $\mathrm{UI} / \mathrm{ml}, 0.09 \mathrm{UI} / \mathrm{ml}$ and $0.09 \mathrm{UI} / \mathrm{ml}$ among first, second and third trimester respectively, and $85.22 \%$ had normal values for TPO antibody. ${ }^{27}$ Our findings suggest that there was mild autoimmunity towards TPO protein in the study population. Although during reproductive age thyroid autoantibodies are found in $5-15 \%$ of women, they are not necessarily accompanied by thyroid dysfunction. ${ }^{28}$ In the present study too, we did not observe thyroid dysfunction in women with positive anti-TPO. However, many other findings suggest that women with thyroid antibodies have risk of becoming hypothyroid during pregnancy and the presence of thyroid antibodies is a powerful risk marker for transition from subclinical to overt hypothyroidism. ${ }^{6}$

We observed adequate iodine nutrition in pregnant women, but high rate of mild thyroid dysfunction. Overt hypothyroidism and overt hyperthyroidism has deleterious effects on pregnancy, and now it has been ascertained about the adverse effects of subclinical hypothyroidism on mother and fetus as well. ${ }^{4}$ Thus, screening for thyroid function during pregnancy would be beneficial for better pregnancy outcomes. Our study had some limitations; the sample size was small and anti-TPO positive women were not followed up for future development of thyroid disorder. Thus, future studies are needed with large sample to determine the burden of thyroid dysfunction in Nepalese pregnant women and its subsequent impact on child and mother health.

\section{CONCLUSIONS}

The study revealed that most women during pregnancy had sufficient iodine nutrition over period of time; while some women had recent inadequate iodine intake. However, thyroid dysfunction particularly subclinical hypothyroidism seemed to be common, and autoimmunity against TPO enzyme persisted among small portion of Nepalese pregnant women population.

\section{REFERENCES}

1. Khatiwada S, Lamsal M, Gelal B, Gautam S, Nepal AK, Brodie D, et al. Anemia, Iron Deficiency and Iodine Deficiency among Nepalese School Children. Indian J Pediatr. 2015;83(7):617-21.[PubMed]

2. Zimmermann MB. The effects of iodine deficiency in pregnancy and infancy. Paediatr Perinat Epidemiol. 2012;26(1):108-17.[PubMed]

3. Stagnaro-Green A, Abalovich M, Alexander E, Azizi F, Mestman J, Negro R, et al. Guidelines of the American Thyroid Association for the diagnosis and management of thyroid disease during pregnancy and postpartum. Thyroid. 2011;21(10):1081-125.[PubMed]

4. Altomare M, LaVignera S, Asero P, Recupero D, Condorelli RA, Scollo P, et al. High prevalence of thyroid dysfunction 
in pregnant women. J Endocrinol Invest. 2013;36(6):40711.[PubMed]

5. Habimana L, Twite KE, Daumerie C, Wallemacq P, Donnen P, Kalenga MK, et al. High prevalence of thyroid dysfunction among pregnant women in Lubumbashi, Democratic Republic of Congo. Thyroid. 2014;24(3):56875.[PMC free article]

6. Lazarus JH. Thyroid function in pregnancy. Br Med Bull. 2011;97(1):137-48.[PubMed]

7. Kayode OO, Odeniyi IA, Iwuala S, Olopade OB, Fasanmade OA, Ohwovoriole AE. Thyroid autoimmunity in pregnant Nigerians. Indian J EndocrinolMetab. 2015;19(5):620-4. [PMC free article]

8. Nepal AK, Khatiwada S, Shakya PR, Gelal B, Lamsal $\mathrm{M}$, Brodie $\mathrm{D}$, et al. Iodine status after iodized salt supplementation in school children of eastern Nepal. Southeast Asian J Trop Med Public Health. 2013;44(6):1072-8.[PubMed]

9. Khatiwada S, Gelal B, Gautam S, Lamsal M, Baral N. Iodine Status among School Children of remote Hilly regions of Nepal. Indian Pediatr. 2015;52(5):436-7.[PubMed]

10. Khatiwada S, Gelal B, Shakya PR, Lamsal M, Baral N. Urinary Iodine Excretion among Nepalese School Children in Terai Region. Indian J Pediatr. 2016;83(1):15-7. [Link]

11. Shakya PR, Gelal B, Das BK, Lamsal M, Pokharel PK, Nepal AK, et al. Urinary iodine excretion and thyroid function status in school age children of hilly and plain regions of Eastern Nepal. BMC Res Notes. 2015;8:374. [PubMed]

12. Ohashi T, Yamaki M, Pandav CS, Karmarkar MG, Irie M. Simple microplate method for determination of urinary iodine. Clin Chem. 2000;46(4):529-36.[PubMed]

13. Schulze KJ, West KP Jr, Gautschi LA, Dreyfuss ML, LeClerq SC, Dahal BR, et al. Seasonality in urinary and household salt iodine content among pregnant and lactating women of the plains of Nepal. Eur J Clin Nutr. 2003;57(8):969-76.[PubMed]

14. Lean MI, Lean ME, Yajnik CS, Bhat DS, Joshi SM, Raut $\mathrm{DA}$, et al. Iodine status during pregnancy in India and related neonatal and infant outcomes. Public Health Nutr. 2014;17(6):1353-62.[PubMed]

15. Grewal E, Khadgawat R, Gupta N, Desai A, Tandon N. Assessment of iodine nutrition in pregnant north Indian subjects in three trimesters. Indian J Endocrinol Metab. 2013;17:289-93.[PMC free article]

16. Ma ZF, Skeaff SA. Thyroglobulin as a biomarker of iodine deficiency: a review. Thyroid. 2014;24(8):1195-209.

\section{[PubMed]}

17. Yoganathan T, Hettiarachchi M, Arasaratnam V, Liyanage C. Maternal iodine status and the thyroid function of pregnant mothers and their neonates in Jaffna District of Sri Lanka. Indian J Endocrinol Metab. 2015;19:817-23. [PMC free article]

18. Raverot V, Bournaud C, Sassolas G, Orgiazzi J, Claustrat F, Gaucherand P, et al. Pregnant French women living in the Lyon area are iodine deficient and have elevated serum thyroglobulin concentrations. Thyroid. 2012;22(5):522-8. [PubMed]

19. Khatiwada S, Gelal B, Tamang MK, Kc R, Singh S, Lamsal M, Baral N. Iodized Salt Use and Salt Iodine Content among Household Salts from Six Districts of Eastern Nepal. J Nepal Health Res Counc. 2014;12(28):191-4. [PubMed]

20. Khatiwada S, Sah SK, KC R, Baral N, Lamsal M. Thyroid dysfunction in metabolic syndrome patients and its relationship with components of metabolic syndrome. Clin Diabetes Endocrinol. 2016;2:3. [Link]

21. Khatiwada S, KC R, Sah SK, Khan SA, Chaudhari RK, Baral N, et al. Thyroid Dysfunction and Associated Risk Factors among Nepalese Diabetes Mellitus Patients. Int J Endocrinol. 2015;2015:570198.[Link]

22. Khatiwada S, KC R, Gautam S, Lamsal M, Baral N. Thyroid dysfunction and dyslipidemia in chronic kidney disease patients. BMC Endo cr Disord. 2015;15:65. [PMC free article]

23. Khatiwada S, Gelal B, Baral N, Lamsal M. Association between iron status and thyroid function in Nepalese children. Thyroid Res. 2016;9:2. [PMC free article]

24. Singh KP, Singh HA, Kamei H, Devi LM. Prevalence of Hypothyroidism among Pregnant Women in the SubMountain State of Manipur. Int J Sci Stud. 2015;5(5):1436.[Full Article]

25. Mandal RC, Bhar D, Das A, Basunia SR, Kundu SB, Mahapatra C. Subclinical hypothyroidism in pregnancy: an emerging problem in Southern West Bengal: a crosssectional study. J Nat Sci Biol Med. 2016;7:80-4.[PMC free article]

26. Rajput R, Goel V, Nanda S, Rajput M, Seth S. Prevalence of thyroid dysfunction among women during the first trimester of pregnancy at a tertiary care hospital in Haryana. Indian J EndocrinolMetab. 2015;19(3):416-9. [PubMed]

27. Bocos-Terraz JP, Izquierdo-Alvarez S, Bancalero-Flores JL, Alvarez-Lahuerta R, Aznar-Sauca A, Real-López E, et al. Thyroid hormones according to gestational age in 
pregnant Spanish women. BMC Res Notes. 2009 Nov 26;2:237. [PubMed]

28. Alavi A, Adabi K, Nekuie S, Jahromi EK, Solati M, Sobhani A, et al. Thyroid dysfunction and autoantibodies association with hypertensive disorders during pregnancy. J Pregnancy. 2012;2012:742695.[Link] 